\title{
A Study of Correlation between Intra-abdominal Fat and Lipid Profiles and Some Anthropometric Parameters in Vegetarian and Non-vegetarian Middle Aged Women of Jabalpur, Madhya Pradesh
}

\author{
Neha Jain, Shyamal Koley* and J.S. Sandhu \\ Department of Sports Medicine and Physiotherapy, Guru Nanak Dev University, \\ Amritsar 143 005, Punjab, India \\ *E-mail:drkoley@yahoo.co.uk
}

KEYWORDS Serum cholesterol, Triglycerides, HDL-C, LDL-C, VLDL-C

\begin{abstract}
In this cross-sectional study, forty seven randomly collected middle aged vegetarian ( $\mathrm{n}=30$ ) and nonvegetarian $(n=17)$ women between the age group 40 - 60 years of Jabalpur, Madhya Pradesh, India, were included to measure height, weight, BMI, intra- abdominal fat, five skinfold measurements, viz. biceps, triceps, subscapular, suprailiac and abdominal and seven lipid profiles, viz. serum cholesterol, High Density Lipoprotein-C (HDL-C), Low Density Lipoprotein-C (LDL-C), Triglycerides, VLDL-C, Total Cholesterol : High Density Lipoprotein-C ratios and Low Density Lipoprotein - C : High Density Lipoprotein-C ratios. Results indicate statistically significant positive correlations between intra-abdominal fat, and weight and BMI for both vegetarian ( $\mathrm{r}=0.32$ and 0.34 respectively) and non-vegetarian $(\mathrm{r}=0.48$ and 0.63 respectively) middle aged women $(\mathrm{P}<0.01)$ also in biceps skinfold ( $\mathrm{r}=0.43$ ). In lipid profiles, negative correlations were observed between intra-abdominal fat and HDL-C both in vegetarian $(\mathrm{r}=-0.25)$ and non-vegetarian $(\mathrm{r}=-0.17)$ middle aged women, though the differences were statistically non-significant.
\end{abstract}

\section{INTRODUCTION}

Indian population has a very high incidence of ischemic heart disease with lipid profile is one of the risk factors which is different from those seen in western populations. Elevated levels of triglyceride, cholesterol and LDL-C are documented as risk factors for atherogenesis. Blood level of HDL-C in contrast, bears an inverse relationship for the risks of atherosclerosis and coronary heart disease. Different plasma lipids vary significantly in various population groups due to differences in geographical, cultural, economical, social conditions. Intra-abdominal fat, however, is probably more important than overall weight as a cardio vascular risk factor (Rimm et al. 1995; Montague and O'Rahilly 2000). As described by Vague in 1956, an android fat distribution (abdominal obesity, or "apple shaped" body) is related to an increased risk of cardiovascular disease. Intra-abdominal fat increases insulin resistance and the related cluster of metabolic risk factors (glucose intolerance or diabetes mellitus, low HDL-cholesterol concentrations, elevated trigylglycerol concentrations, hypertension, and obesity) (Reaven 1988; Pascot et al. 2000; Arora et al. 2007). This cluster was first described by Reaven (1988) as "syndrome
$\mathrm{X}$ " and is also referred to as the "insulin resistance syndrome" or "metabolic syndrome" (Despres 1993).

Diabetes mellitus has become a widespread disease nowadays. According to World Health Organization report (1998), around 171,000,000 people were affected with diabetes worldwide by the year 2000 and will reach around 366,000,000 by the year 2030. The prevalence of diabetes is on the rise, more alarmingly in the developing nations. In India alone 31,705,000 people were affected by the year 2000 and will reach around $79,441,000$ by the year 2030 . Due to the high degree of genetic predisposition and high susceptibility to environmental conditions, characterized by a low BMI, high upper body adiposity, a high body fat percentage and a high level of insulin resistance, Indian population faces higher risk for diabetes and its complications (Rosenson 2005). The waist to hip ratio is commonly used as an indirect measure of lower and upper body fat distribution. Young adults with waist to hip ratios in excess of 0.94 for men and 0.82 for women are at high risk for adverse health consequences (Bray and Gray 1988). Janssen et al. (2002) opined that body mass index and waist circumference independently contributed to the prediction of abdominal, subcutaneous and visceral fat. 
Evidence in the literature has suggested that the visceral fat thickness measured by ultrasonography could be more reliable method to quantify visceral fat as compared with other methods (Armellini et al. 1993; Tornaghi et al. 1994).

Association of lipid profiles is reported with lifestyle ( Twisk et al. 1998; Serter et al. 2004), age ( Maki et al. 1997), intra-abdominal adiposity ( Mannabe et al. 1999; Mari et al. 1999), obesity (Despres et al. 1985; Denke et al. 1993; Dongsheng et al. 2000; Pihl and Jurimae 2001), BMI (Bertolli et al. 2003) and waist to hip ratios (Okosun et al. 2000; Dalton et al. 2003; Lopatynski et al. 2003). In the present study, an attempt has been made to investigate the relationship of intra-abdominal fat with lipid profiles along with some anthropometric variables in vegetarian and nonvegetarian middle aged women of Jabalpur, Madhya Pradesh.

\section{MATERIALS AND METHODS}

The study was conducted within the framework of an ongoing prospective cohort study of vegetarian and non-vegetarian middle aged women of Jabalpur, Madhya Pradesh. Women were recruited from a Health check-up camp organized by Digambar Jain Mahila Samiti and Punjabi Mahila Samiti at the Gorakhpur gurudwara, Jabalpur between $27^{\text {th }}$ June $-27^{\text {th }}$ July, 2007. A total of 47 middle aged (between 40-60 years) women participated in the study. A total of 30 vegetarian Jain middle aged women and 17 non-vegetarian Punjabi middle aged women with a body mass index (BMI) $\geq 30 \mathrm{~kg} / \mathrm{m}^{2}$ were screened for inclusion in the study. Exclusion criteria included self reported pregnancy, any chronic infectious disease, weight loss $>6 \mathrm{kgs}$ during past 6 months. The study was approved by Institutional Ethical Committee and a written informed consent was obtained from all the participants.

In this cross-sectional study, all participants had their anthropometric data measured only in the morning time by NJ. Measurement of weight to the nearest of $0.1 \mathrm{~kg}$ by a weighing machine and height to the nearest of $0.1 \mathrm{~cm}$ by an anthropometer were done. BMI was calculated as weight (in $\mathrm{kg}$ ) divided by height (in meter $^{2}$ ) as indicated by World Health Organization. A pretested semi structured questionnaire was developed to obtain information on the demographic, nutritional and lifestyle profiles of the participants.

Venous blood samples were taken from all the subjects in the morning after fasting overnight. Plasma levels of fasting plasma glucose, total cholesterol, triglycerides, High Density Lipoprotein- Cholesterol (HDL-C), Low Density Lipoprotein-Cholesterol (LDL-C) and Very Low Density Lipoprotein (VLDL) were analyzed. Total cholesterol and triglyceride concentrations were determined with a semi-automated enzymatic analyzer (RA 50, Semi-auto Chemistry Analyzer, Thyrocare India Ltd, and India). HDL-Cholesterol serum level was measured by using phosphotungstate precipitation method. The ratio of total cholesterol-to-high density lipoprotein cholesterol (HDL-C) is considered to be the best predictor of heart disease and has been used in our study. Exclusion factors were confirmed from the subject's personal physician report and a detailed history.

The amount of abdominal adipose tissue was measured ultrasonographically by a real time US scanner, Sonoline Prima, Siemens, Germany. Statistical analyses were performed using the SPSS software (version 14.0). Comparisons between variables were determined by using student's $t$ test. Correlations were tested by the Pearson correlation coefficient test.

\section{RESULTS AND DISCUSSION}

Table 1 shows the distribution of mean values and standard deviations of 16 variables in middle aged vegetarian and non-vegetarian women of Jabalpur, Madhya Pradesh. The middle aged vegetarian women have higher mean values in height $(159.40 \mathrm{~cm})$, weight $(63.20 \mathrm{Kg})$, biceps skinfold (13.88 mm), triceps skinfold $(24.12 \mathrm{~mm})$, Suprailiac skinfold ( $23.68 \mathrm{~mm})$, abdominal skinfold (32.92 mm), serum cholesterol (186.67 mg/dl), serum triglyceride $(142.21 \mathrm{mg} / \mathrm{dl})$, serum LDL-C (108.25 mg/dl), serum VLDL (27.78 mg/dl), ratio of total cholesterol: HDL-C (3.75), ratio of LDL-C: HDL-C (2.18), ultrasonographic intra-abdominal fat $(60.33 \mathrm{~mm})$ as compared to middle aged nonvegetarian women $(155.24 \mathrm{~cm}, 62.76 \mathrm{Kg}, 13.36 \mathrm{~mm}$, $22.05 \mathrm{~mm}, 23.32 \mathrm{~mm}, 31.32 \mathrm{~mm}, 177.29 \mathrm{mg} / \mathrm{dl}$, $122.34 \mathrm{mg} / \mathrm{dl}, 101.63 \mathrm{mg} / \mathrm{dl}, 24.47 \mathrm{mg} / \mathrm{dl}, 3.54,2.18$ respectively). Conversely, the middle aged vegetarian women have lower mean values in BMI $\left(24.81 \mathrm{Kg} / \mathrm{m}^{2}\right)$, sub scapular skinfold $(25.75 \mathrm{~mm})$ and serum HDL-C (50.64 mg/dl), than their nonvegetarian counterparts $\left(25.87 \mathrm{Kg} / \mathrm{m}^{2}, 26.74 \mathrm{~mm}\right.$ and $51.20 \mathrm{~mm}$ respectively). However, statistically no significant differences $(\mathrm{P}>0.05)$ were found 
Table 1: Distribution of mean values and standard deviation of 16 parameters in vegetarian and nonvegetarian middle age menopausal women.

\begin{tabular}{|c|c|c|c|c|c|c|c|}
\hline \multirow[t]{2}{*}{ Parameters } & \multicolumn{3}{|c|}{$\begin{array}{l}\text { Vegetarian middle } \\
\text { aged women }(N=30)\end{array}$} & \multicolumn{3}{|c|}{$\begin{array}{l}\text { Non-vegetarian middle } \\
\text { aged women }(N=17)\end{array}$} & \multirow[t]{2}{*}{ ' $t$ ' value } \\
\hline & Mean & S.D. & S.E. & Mean & S.D. & S.E. & \\
\hline Height $(\mathrm{cm})$ & 159.40 & 5.88 & 1.07 & 155.24 & 8.56 & 2.08 & 1.97 \\
\hline Weight (kg) & 63.20 & 10.97 & 2.00 & 62.76 & 13.15 & 3.19 & 0.12 \\
\hline $\operatorname{BMI}\left(\mathrm{kg} / \mathrm{m}^{2}\right)$ & 24.81 & 3.91 & 0.71 & 25.87 & 4.15 & 1.01 & -0.88 \\
\hline Bicep skinfold (mm) & 13.88 & 3.50 & 0.64 & 13.36 & 3.61 & 0.87 & 0.49 \\
\hline Triceps skinfold (mm) & 24.12 & 5.36 & 0.98 & 22.05 & 4.44 & 1.08 & 1.35 \\
\hline Subscapular skinfold (mm) & 25.75 & 5.96 & 1.09 & 26.74 & 5.35 & 1.30 & -0.56 \\
\hline Suprailiac skinfold (mm) & 23.68 & 5.93 & 1.08 & 23.32 & 5.11 & 1.24 & 0.21 \\
\hline Abdominal skinfold (mm) & 32.92 & 5.76 & 1.05 & 31.32 & 5.35 & 1.30 & 0.93 \\
\hline S. Cholesterol $(\mathrm{mg} / \mathrm{dl})$ & 186.67 & 38.32 & 7.00 & 177.29 & 33.90 & 8.22 & 0.84 \\
\hline S.HDL (mg/dl) & 50.64 & 8.78 & 1.60 & 51.20 & 8.97 & 2.18 & -0.20 \\
\hline S. Triglyceride (mg/dl) & 142.21 & 70.13 & 12.80 & 122.34 & 40.63 & 9.85 & 1.07 \\
\hline S.LDL (mg/dl) & 108.25 & 32.08 & 5.86 & 101.63 & 28.07 & 6.81 & 0.71 \\
\hline S. VLDL (mg/dl) & 27.78 & 12.21 & 2.23 & 24.47 & 8.13 & 1.97 & 1.00 \\
\hline TC/HDL ratio & 3.75 & 0.83 & 0.15 & 3.54 & 0.76 & 0.18 & 0.89 \\
\hline LDL/HDL ratio & 2.18 & 0.69 & 0.13 & 2.04 & 0.65 & 0.16 & 0.66 \\
\hline Intra abdominal fat (mm) & 60.33 & 13.00 & 2.37 & 58.35 & 16.45 & 3.99 & 0.46 \\
\hline
\end{tabular}

in any case between those two sets of populations.

The correlation coefficients $(r)$ of intraabdominal fat and 15 other variables in vegetarian and non-vegetarian middle aged women of Jabalpur, Madhya Pradesh, were shown in Table 2 . In vegetarian middle aged women, statistically significant positive correlations $(\mathrm{p} \leq 0.05)$ were noted between intra-abdominal fat and weight $(\mathrm{r}=0.32)$, BMI $(\mathrm{r}=0.34)$ and non-significant negative correlations were observed between intra-abdominal fat and triceps skinfold $(r=-0.09)$ and serum HDL-C ( $\mathrm{r}=-0.25)$. Whereas, in nonvegetarian middle aged women, statistically significant positive correlations $(\mathrm{p} \leq 0.05)$ were found between intra-abdominal fat and weight $(\mathrm{r}=0.48), \mathrm{BMI}(\mathrm{r}=0.63)$ and biceps skinfold $(\mathrm{r}=0.43)$. Intra-abdominal fat showed negative correlations (though statistically non-significant) with serum HDL-C ( $\mathrm{r}=-0.05)$, serum triglyceride $(\mathrm{r}=-0.11)$ and serum VLDL ( $\mathrm{r}=-0.11)$ among them.

Early post menopausal status is associated with a preferential increase in intra-abdominal fat that is independent of age and total body fat mass. This increased visceral fat accumulation in women can be attributed to the increased androgenic activity in the postmenopausal women as the hormones are known to affect the fat distribution (Kotani 1994; Vague 1947). Preliminary studies suggest that the menopause transition is associated with deleterious changes in body composition and body fat distribution. The association between body fat distribution and lipid profile has been shown to be the important predictor for metabolic disturbances including dyslipidemia, hypertension, diabetes, cardio vascular disease etc.

In the present study, anthropometric parameters, viz. height, weight, BMI, biceps skinfold, triceps skinfold, subscapular skinfold, suprailiac skinfold and abdominal skinfold were not the affected factors among vegetarian and nonvegetarian middle aged women (Table 1). Weight was one such factor that affects greatly towards metabolic risk. In fact, it was reported earlier too, that weight loss and/or gain was related to increased risk for abdominal fat distribution and therefore metabolic risk profile (Phil and Jurimae 2001). No marked mean differences were found in the distribution of serum cholesterol, serum HDL$\mathrm{C}$, serum triglyceride, serum LDL-C, serum VLDL, ratio of total cholesterol: HDL-C and ratio of LDL$\mathrm{C}$ : HDL-C in vegetarian and non-vegetarian middle aged women as data was collected from same geographical and socio-economic background. Elevation in any one of the components of lipid, except HDL-C, plays an important role in development of coronary heart diseases. The present study showed statistically no marked differences among all the lipid components as obesity was frequently present among middle aged vegetarian and non-vegetarian women, thus blood lipid levels altered homogenously. It showed that the increase in LDL-C and total cholesterol makes the individual more prone to metabolic risk profile (Martinez et al. 2001). 
Table 2: Correlation coefficients $(r)$ of intraabdominal fat and other 15 variables in vegetarian and non-vegetarian middle aged women.

\begin{tabular}{lccc}
\hline Parameters & $\begin{array}{c}\text { Vege- } \\
\text { tarian } \\
(N=30)\end{array}$ & $\begin{array}{c}\text { Non- } \\
\text { vegetarian } \\
(N=17)\end{array}$ & Total \\
& $(N=47)$ \\
\hline Height (cm) & 0.021 & 0.053 & 0.054 \\
Weight (kg) & $0.316^{*}$ & $0.477 *$ & $0.389 * *$ \\
BMI (kg/m²) & $0.339^{*}$ & $0.634^{*} *$ & $0.449 * *$ \\
Bicep skinfold (mm) & 0.186 & $0.435 *$ & $0.292^{*}$ \\
Triceps skinfold (mm) & -0.089 & 0.332 & 0.076 \\
Subscapular skinfold (mm) & 0.159 & 0.286 & 0.198 \\
Suprailiac skinfold (mm) & 0.143 & 0.128 & 0.136 \\
Abdominal skinfold (mm) & 0.168 & 0.327 & 0.234 \\
S. Cholesterol (mg/dl) & 0.017 & 0.243 & 0.109 \\
HDL-C(mg/dl) & -0.255 & -0.051 & -0.171 \\
S. Triglyceride (mg/dl) & 0.047 & -0.111 & 0.012 \\
LDL-C (mg/dl) & 0.067 & 0.342 & 0.174 \\
S. VLDL (mg/dl) & 0.059 & -0.111 & 0.015 \\
TC/HDL-C ratio & 0.222 & 0.264 & 0.242 \\
LDL-C/HDL-C ratio & 0.210 & 0.330 & $0.260 *$ \\
\hline
\end{tabular}

*indicates $\mathrm{P}<0.05 ; * *$ indicates $\mathrm{P}<0.01$

In this study, intra-abdominal fat was found to be negatively related to HDL-C in both vegetarian and non-vegetarian middle aged women (Table 2). HDL-C is known to be good cholesterol (Castelli et al. 1988). Reduction in plasma HDL-C impairs the normal clearance from arterial wall thereby accelerating the development of atherosclerosis (Miller and Miller 1975). Improvement of HDL-C helps provides protective effect on heart. The present study is in agreement with the findings of Freedman et al. (1985), Imamura et al. (1993) and Menace et al. (1999) on relationship between fat distribution and serum lipids.

\section{REFERENCES}

Armellini F, Zamboni M, Robbi R, Todesco T, Rigo L, et al. 1993. Total and intra-abdominal fat measurements by ultrasound and computerized tomography. Int J Obes Relat Metab Disord, 17: 209-214.

Arora M, Koley S, Gupta S, Sandhu JS 2007. A study on lipid profile and body fat in patients with diabetes mellitus. The Anthropologists, 9: 295-298.

Ashwell M, Cole TJ, Dixon AK 1985. Obesity: New insight into the anthropometric classification of fat distribution shown by computed tomography. $\mathrm{Br}$ Med J, 290: 1692-1694.

Bertolli A, Di-Daniele N, Ceccobelli M, Ficara A, Girasoli C et al. 2003. Lipid profile, BMI, body fat distribution and aerobic fitness in men with metabolic syndrome. Acta Diabetol, 40: S130-S133.

Bray GA, Gray DS 1988. Obesity. Part I - Pathogenesis. Western J Med, 149: 429-441.

Castelli WP 1988. Cardiovascular diseases in women. Am J Obstet Gynecol, 158: 1553-1560.

Dalton M, Cameron AJ, Zimmet PZ, Shaw JE, Jolley J et al. 2003. Waist circumferences, waist-hip ratio and body mass index and their correlation with cardiovascular disease risk factors in Australian adults. J Intrn Med, 254: 555-563.

Denke MA, Sempos CT, Grundy SM 1993. Excess body weight: An under- contributor to high blood cholesterol in White American men. Arch Int Med, 153: 1093-1103.

Despres JP, Allard C, Tremblay A, Talbot J, Bouchard C 1985. Evidence for a regional component of body fatness in association with serum lipids in men and women. Metabolism, 34: 967-973.

Després JP 1993. Abdominal obesity as important component of insulin-resistance syndrome. Nutrition, 9: 452-459.

Dongsheng H, Judy H, Stuart R, Gray K, Jablonski A et al. 2000. Effects of obesity and body fat distribution on lipids and lipoproteins in nondiabetic American Indians: The Strong Heart Study. Obesity Research, 8: 411-421.

Fujioka S, Matsuzawa Y, Tokunaga K, Tarui S 1988. Contribution of intra-abdominal fat accumulation to the impairment of glucose and lipid metabolism in human obesity. Metabolism, 36: 54-57.

Imamura T, Kano H, Shin K, Konjiki O, Ohsawa $\mathrm{Y}$ et al. 1993. Relationship between abdominal fat distribution assessed by computed tomography and serum lipids in elderly. Nippon Ronen Igakkai Zasshi, 30: 123-129.

Janssen I, Heymsfield SB, Allison DB, Kotler DP, Ross R 2002. Body mass index and waist circumference independently contribute to the prediction of nonabdominal, abdominal subcutaneous, and visceral fat. Am J Clin Nutr, 75: 683-688.

Kotani KK 1994. Sexual dimorphism of age related changes in whole body fat distribution in the obese. Int J Metab Disord, 18: 207-211.

Lopatynski J, Mardarowixz G, Szczesniak G 2003. A comparative evaluation of waist circumference, waist to hip ratio, waist to height ratio and body mass index as indicators of impaired glucose tolerance and as risk factors for type 2 diabetes mellitus. Ann Univ Mariae Cuire Sklodowska, 58: 413-419.

Maki KC, Kritsch K, Foley S, Soneru I, Davidson MH 1997. Age dependence of the relationship between adiposity and serum LDL-C in men. J Am Clin Nutr, 16: $578-583$.

Mannabe E, Aoyagi K, Tachibana H, Takemoto T 1999. Relationship of intra- abdominal adiposity and peripheral fat distribution to lipid metabolism in an island population in western Japan: gender differences and effect of menopause. Tohoku J Exp Med, 188: 189-202.

Mari O, Furuya R, Ohkawa S, Yoneyama T, Nisikino M et al. 1999. Altered abdominal fat distribution and its association with serum lipid profile in nondiabetic haemo-dialysis patients. Nephrol Dial Transplant, 14: 2427-2432.

Martinez CA, Ramos R, Gonzalez MT, Castineiras MJ 2002. Dyslipidemia and cardiovascular risk factors in type 2 diabetes mellitus patients with associated diabetic nephropathy. Nefrologia, 22: 51-58.

Miller GJ, Miller NE 1975. Plasma high density lipoprotein concentration and development of ischaemic heart disease. Lancet, 1: 16-19. 
Montague CT, O'Rahilly S 2000. The perils of portliness: Causes and consequences of visceral adiposity. Diabetes, 49: 883-888.

Okosun S, Richard ICS, Richard BO, Cooper S, Forrester $\mathrm{T}$ 2000. Association of waist circumference with risk of hypertension and type 2 Diabetes in Nigerians, Jamaicans and African-Americans. Diabetes Care, 21: $1836-1842$.

Pascot A, Despres JP, Lemieux I 2000. Contribution of visceral obesity to the deterioration of the metabolic risk profile in men with impaired glucose tolerance. Diabetologia, 43: 1126-1135.

Pihl E, Jurimae T 2001. Relationship between body weight change and cardiovascular risk factors in male former athletes. Int J Obes Relat Metab Disord, 25: 10571062.

Reaven GM 1988. Role of insulin resistance in human disease. Diabetes, 37: 1595-1607.

Ribeiro-Filho FF, Faria AN, Kohlmann O, Ajzen S, Rebeiro $\mathrm{AB}$ et al. 2001. Ultrasonography for the evaluation of visceral fat and cardiovascular risk. Hypertension, 38: 713-717.

Rimm EB, Stampfer MJ, Giovannucci E 1995. Body size and fat distribution as predictors of coronary heart disease among middle-aged and older US men. Am J Epidemiol, 141: 1117-1127.
Rosenson RS 2005. HDL-C and the diabetic patients: Target for therapeutic intervention. Diabetes Res Clin Pract, 68: 36-42.

Serter R, Demirbas B, Korukluoslu B, Culha C, Cakal E et al. 2004. The effect of L-thyroxine replacement therapy on lipid based cardiovascular risk in subclinical hypothyroidism. J Endocrinol Invest, 27: 897-903.

Tornaghi G, Raiteri R, Pozzato C, Rispoili A, Bramani M et al. 1994. Anthropometric or ultrasonic measurements in assessment of visceral fat? A comparative study. Int J Obes Relat Metab Disord, 18: 771-775.

Twisk JW, Kemper HC, Van Mechelen W, Post GB, Van Lenthe FJ 1998. Body fatness: longitudinal relationship of BMI and the sum of skinfolds with other risk factors for CHD. Int J Obes Relat Metab Disord, 22: 915-922.

Vague J 1947. La differentiation sexuelle-facteur determinant des formes de 1'obesite'. Presse Med, 30: $339-340$.

Vague J 1956. The degree of masculine differentiation of Obesities: A factor determining predisposition to diabetes, atherosclerosis, gout and uric calculus disease. Am J Clin Nutr, 4: 20-34.

World Health Organization 1998. Obesity: Preventing and Managing the Global Epidemic: Report of a WHO Consultation on Obesity. Geneva: WHO. 